\title{
Educational differences in the validity of self-reported physical activity
}

\author{
Annemarie N. E. Winckers ${ }^{1}$, Joreintje D. Mackenbach', Sofie Compernolle², Mary Nicolaou', \\ Hidde P. van der Ploeg ${ }^{4}$, Ilse De Bourdeaudhuij ${ }^{2}$, Johannes Brug ${ }^{1}$ and Jeroen Lakerveld ${ }^{1^{*}}$
}

\begin{abstract}
Background: The assessment of physical activity for surveillance or population based studies is usually done with self-report questionnaires. However, bias in self-reported physical activity may be greater in lower educated than in higher educated populations. The aim of the present study is to describe educational differences in the validity of self-reported physical activity.

Methods: We included 196 healthy adults (age $57 \pm 15.4$, of whom $17 \%$ low, $24 \%$ medium and $59 \%$ high educated). Criterion validity of an adapted International Physical Activity Questionnaire was assessed against the ActiGraph GT3X+ accelerometer.

Results: While criterion validity of self-reported physical activity was low to moderate in the total sample (Spearman rho ranged from 0.16 to 0.27 , depending on the variables used), the validity in lower educated respondents was poor (-0.07 to 0.05$)$.

Conclusions: The results confirm the hypothesis that self-report physical activity questionnaires are less valid in lower educated populations.
\end{abstract}

Keywords: Accelerometer, Education level, Questionnaire, Self-report, Validity, Physical activity

\section{Background}

Lack of physical activity (PA) is an important health behaviour that has been posed as a risk factor for obesity, cardiovascular diseases and other chronic diseases [1]. Self-report questionnaires are most often used to assess PA at population levels. Although objective assessment methods such as accelerometry provide more accurate measures of PA, they are relatively expensive and hence not always practical in larger-scale cohorts [2]. Questionnaires are able to assess PA in different domains, while thus far accelerometers do not distinguish between transport-related physical activities, organised sports, household PA or occupational PA. Thus, a questionnaire may be preferred over (or next to) the use of accelerometers. However, reporting bias, including recall and social desirability bias, often leads to over-reporting and double counting of PA [3, 4]. Recalling PA is viewed as a

\footnotetext{
* Correspondence: j.lakerveld@vumc.nl

${ }^{1}$ Department of Epidemiology and Biostatics, EMGO Institute for Health and Care Research, VU University Medical Center Amsterdam, De Boelelaan 1089a, 1081HV, Amsterdam, The Netherlands

Full list of author information is available at the end of the article
}

highly complex cognitive task [5]. As typical PA questionnaires require respondents to recall and add-up different levels of PA in different domains over a period of time in the recent past, lower educated individuals may have more difficulties with interpreting and answering these questions. Moreover, there are indications that social desirability bias is larger in lower educated than in higher educated individuals. For example, a study among 81 US women showed that individuals who scored higher on the personality trait 'social desirability' had higher over-reporting of their PA levels, and lower educated women were more likely to have the 'social desirability' trait [6]. The validity of self-reported PA may therefore differ between educational groups.

However, it is not clear whether such educational differences exist. Systematic reviews on the validity of PA questionnaires do not mention differences between educational groups [7-10] while individual studies' findings are equivocal. For example, in a population-based sample of 418 Swedish adults, low education was a significant predictor of overestimation of usual daily PA [11]. 
In a Dutch sample of 286 adolescents and 332 young adults, educational differences were observed in adolescents only, with lower educated individuals being less likely to over-report PA [12]. If over-reporting is consistent across educational groups, self-reported PA may still allow researchers to examine relative PA differences across educational groups. If not, the validity of selfreport instruments may be compromised. Researchers may want to make an informed choice for using objective or subjective measures, based on the characteristics of their study population. In this study, we explored differences in self-reported and measured PA, and compared the validity of self-reported PA across educational groups.

\section{Methods}

\section{Recruitment of participants}

This study was conducted as part of the cross-European project 'Sustainable prevention of obesity through integrated strategies - SPOTLIGHT' [13]. A total of 6037 participants from 60 neighbourhoods in five countries participated in an online survey [14]. Of the 1609 Dutch participants who completed the survey, 379 left their phone number to be contacted between March and June 2014. Of those who could be reached $(n=305), 62$ were not interested in participating and 41 did not meet the inclusion criteria (i.e. returning the questionnaire or informed consent, being 18 years or older and being able to walk one flight of stairs independently), resulting in a final sample of 202 respondents. The study was approved by the Medical Ethical Committee of the VU Medical Center and all participants to the survey provided informed consent.

\section{Measurements \\ Demographics}

Respondents reported on their age, gender and education. The item on educational level was based on the Dutch Standard Classification of Education (SOI), which is comparable to the International Standard Classification of Education (ISCED) [15]. We divided the nine answering categories into low (no education/completed primary school/ lower vocational education/general secondary education), medium (secondary vocational or higher general secondary education), or high education (university bachelor-education degree or higher) as defined by ISCED.

\section{Self-report physical activity}

Participants were asked to complete a slightly adapted version of the International Physical Activity Questionnaire (IPAQ) long-form. The adaptations included combining two questions on moderate leisure time PA and vigorous leisure time PA into one. Combining moderate and vigorous PA was done to shorten the questionnaire, but also because the moderate and vigorous PA domains are commonly analyzed combined (MVPA). Data was cleaned for missing and out-of-range values according to the IPAQ scoring protocol ([16]) and two variables were derived: 'time spent on MVPA' (in minutes/day) and 'time spent on total PA' (in MET-minutes/day).

\section{Objectively measured physical activity}

Participants were asked to wear a tri-axial accelerometer (ActiGraph GT3X+), fixed to an elastic belt on the right hip, for seven consecutive days during waking hours. Non-wear time was defined as $60 \mathrm{~min}$ of consecutive zeroes, allowing for two interruptions of $<100$ counts per minute. Participants were included in the analysis if they wore the accelerometer for at least ten hours/day on at least five out of seven days. Accelerometer variables were averaged over valid days (wear time $>10 \mathrm{~h} /$ day) and included 'time spent in MVPA' in min/day, 'step counts/day' and 'total counts/day'.

\section{Statistical analysis}

First, ANOVA was applied to compare patterns of selfreported (as measured with the IPAQ) and measured (with accelerometry) MVPA across educational groups. Second, to calculate criterion validity, IPAQ and accelerometry differences were tested using Pearson's correlation coefficient - or Spearman's correlation coefficient in case data was not distributed normally. Criterion validity was calculated for the total sample, as well as for the lower, medium and higher educated group. This allowed for the assessment of differences in criterion validity across educational groups (by eyeballing, as statistical differences between correlation coefficients are often not informative). We compared different selfreport and accelerometry variables (the self-report measures 'time spent in MVPA' and 'time spent on total PA' with accelerometry measures 'time spent in MVPA', 'step counts/day' and 'total counts/day') to check for consistency of the findings.

\section{Results}

Six of 202 participants were excluded from the study as they did not wear the accelerometer $>10 \mathrm{~h} /$ day for at least five days. As a result, a total of 196 participants were included in this study (mean age $57 \pm 15.4$, $57 \%$ women, of whom $17 \%$ low, $24 \%$ medium and $59 \%$ high educated) (see also Table 1). Low, medium and high educated individuals did not differ significantly in either self-reported MVPA (188 $\mathrm{min}$ (SD \pm 126$)$, $193 \mathrm{~min}(\mathrm{SD} \pm 136)$ and $156 \mathrm{~min}(\mathrm{SD} \pm 118)$ respectively, $p=0.17)$ or objectively measured MVPA (26 ( $\mathrm{SD} \pm 23), 27 \mathrm{~min}(\mathrm{SD} \pm 24)$ and $31 \mathrm{~min}(\mathrm{SD} \pm 20)$ per day respectively, $p=0.32$ ). All educational groups 
Table 1 Characteristics of the study sample

\begin{tabular}{|c|c|c|c|c|c|c|c|c|}
\hline \multirow[b]{2}{*}{ General descriptives } & \multicolumn{2}{|c|}{ Total $(n=196)$} & \multicolumn{2}{|c|}{$\begin{array}{l}\text { Lower education } \\
(n=33,17.1 \%)\end{array}$} & \multicolumn{2}{|c|}{$\begin{array}{l}\text { Medium education } \\
(n=47,24.4 \%)\end{array}$} & \multicolumn{2}{|c|}{$\begin{array}{l}\text { Higher education } \\
(n=113,58.5 \%)\end{array}$} \\
\hline & $\mathrm{n}$ & $\begin{array}{l}\text { Mean }( \pm \text { SD) or } \\
\text { number }(\%)\end{array}$ & $n$ & $\begin{array}{l}\text { Mean }( \pm \text { SD) or } \\
\text { number }(\%)\end{array}$ & $n$ & $\begin{array}{l}\text { Mean }( \pm \text { SD) or } \\
\text { number }(\%)\end{array}$ & $n$ & $\begin{array}{l}\text { Mean }( \pm \text { SD) or } \\
\text { number }(\%)\end{array}$ \\
\hline Age (years) & 196 & $57.1( \pm 15.4)$ & 33 & $61.0( \pm 14.5)$ & 47 & $59.9( \pm 15.0)$ & 113 & $54.78( \pm 15.5)$ \\
\hline Gender & 195 & & 33 & & 46 & & 113 & \\
\hline -Men & & $84(43.1 \%)$ & & $18(54.5 \%)$ & & $17(37.0 \%)$ & & $48(42.5 \%)$ \\
\hline -Women & & $111(56.9 \%)$ & & $15(45.5 \%)$ & & $29(63.0 \%)$ & & $65(57.5 \%)$ \\
\hline $\mathrm{BMI}\left(\mathrm{kg} / \mathrm{m}^{2}\right)$ & 189 & $24.8( \pm 4.2)$ & 32 & $26.0( \pm 4.9)$ & 45 & $25.7( \pm 4.6)$ & 110 & $24.2( \pm 3.7)$ \\
\hline Ethnicity & 192 & & 33 & & 47 & & 110 & \\
\hline -Dutch & & $174(90.6 \%)$ & & $31(93.9 \%)$ & & $43(91.5 \%)$ & & $98(89.1 \%)$ \\
\hline -Western immigrant & & $10(5.2 \%)$ & & $1(3.0 \%)$ & & $2(4.3 \%)$ & & $7(6.4 \%)$ \\
\hline -Non-western immigrant & & $8(4.2 \%)$ & & $1(3.0 \%)$ & & $2(4.3 \%)$ & & $5(4.5 \%)$ \\
\hline
\end{tabular}

$S D$ Standard deviation, BMI Body Mass Index

over-reported their MVPA, but this did not significantly differ between low, medium and high educated individuals.

\section{Criterion validity}

Table 2 shows the Spearman's correlation coefficients for the comparison of the IPAQ and accelerometer. For the total sample, PA as measured with the IPAQ showed a relatively low correlation with PA assessed with the accelerometer (Spearman rho ranged from 0.16 to 0.27 , depending on variables used). Stratified analyses showed that correlation coefficients were approximately five times lower in the low educated group compared to the medium and high educated group. The Spearman rho for lower educated individuals suggests that there was almost no agreement between rank in self-reported PA and objectively measured PA.

\section{Discussion}

The results from this study confirm the pre-set hypothesis that criterion validity of self-reported PA is higher in the medium and high education group compared to the lower educated group. Whereas the validity in the high education group could be viewed as acceptable (low to moderate), the even lower validity in the low education group suggests that self-report results in a differential categorisation of individuals on the basis of education level.

We found overestimations of PA in all educational groups, concordant with a previous literature overview [4]. The IPAQ is known to result in over-reporting of PA [9], possible due to its' asking for average times and best estimates of frequencies [17]. It has also been suggested that reporting issues are likely due to social desirability [6] or the inability to correctly assess the intensity

Table 2 Spearman correlation coefficients for the comparison of total physical activity as assessed with IPAQ and ActiGraph

\begin{tabular}{|c|c|c|c|c|c|}
\hline \multicolumn{2}{|l|}{ Variables } & \multicolumn{4}{|c|}{ Spearman correlation coefficients } \\
\hline$\overline{\mathrm{IPAQ}}\left(\mathrm{min}\right.$ day $\left.^{-1}\right)$ & ActiGraph $\left(\right.$ min.day $\left.^{-1}\right)$ & All $(N=196)^{d}$ & $\begin{array}{l}\text { Lower education } \\
(N=33)\end{array}$ & $\begin{array}{l}\text { Medium education } \\
(N=47)\end{array}$ & $\begin{array}{l}\text { Higher education } \\
(N=113)\end{array}$ \\
\hline MVPA & MVPA & $0.157^{*}$ & -0.029 & $0.328^{*}$ & $0.191^{*}$ \\
\hline MVPA & Step counts ${ }^{a}$ & $0.251^{* *}$ & 0.054 & $0.350^{*}$ & $0.297^{* *}$ \\
\hline Total PA ${ }^{b}$ & MVPA & $0.155^{*}$ & -0.074 & $0.299^{*}$ & $0.200^{*}$ \\
\hline MVPA & Total counts ${ }^{c}$ & $0.268^{* *}$ & 0.016 & $0.383^{* *}$ & $0.322^{* *}$ \\
\hline
\end{tabular}

${ }^{\mathrm{a} A c t i G r a p h}$ total step counts

bIPAQ MET min.day ${ }^{-1}$

${ }^{\mathrm{C} A c t i G r a p h}$ counts.day ${ }^{-1}$

${ }^{d}$ For three people, information on educational attainment was missing. The sum of people in low, medium and high education therefore adds up to 193 IPAQ International Physical Activity Questionnaire, MVPA Moderate and Vigorous Physical Activity, PA Physical Activity

${ }^{*} p<0.05$ ** $p<0.01$ 
level of an activity or to accurately recall time spent being active [18]. We did not find statistical significant educational patterns in over-reporting in our study, in contrast to other studies showing more over-reporting of PA in lower than in medium and higher educated individuals $[11,12]$. The lack of significant educational differences in overestimation may have been due to the relatively small group sizes. This is in concordance with two other studies with small samples of low educated individuals: the study of Ekelund and colleagues did not find that education affected the correlation between self-reported and accelerometry-measured PA $[12,19]$, and the study of Rzewnicki concluded that over-reporters of PA were not more likely to be lower or higher educated [12, 17].

The study of Ekelund and colleagues did find that especially individuals with low levels of PA tended to overestimate their PA in a PA questionnaire [19]. It could be that overestimation of self-report PA is high in low educated groups with low levels of PA. The combination of low education and low levels of PA in this sample may therefore partly explain the lower validity for low educated participants as compared to those with higher educational attainment.

Despite lack of strong educational patterns in overreporting of PA in this study, the validity of the selfreport did seem to be affected by educational differences. This suggests that while medium and high educated individuals over-reported their PA, the selfreport questionnaire was still able to rank individuals with low and high PA as such. For low educated individuals, the ranking of individuals according to their selfreported PA level did not correspond with the ranking according to measured PA. The reasons underlying the differential validity of PA self-report across educational groups should be further explored.

A strength of this study is that we included respondents across different educational strata. Our relatively small sample size could be viewed as a limitation, with $83 \%$ of the participants corresponding to the medium or high education group. The relatively small sample of lower educated individuals may have limited the power to detect more pronounced educational differences in PA-specific self-report bias. Generalisation of the results to other PA questionnaires or populations should be done with caution as this study was performed in a Dutch adult population and we only evaluated (an adapted form of) the IPAQ long-form. Other questionnaires may show less education-specific bias.

\section{Conclusion}

In conclusion, we found considerable educational differences in the validity of self-reported PA. These findings suggest that using a self-report questionnaire in the general population (i.e. with a range of educational backgrounds) might introduce a bias that will be stronger in lower educated respondents. Using objective measures to assess PA across a range of educational levels will generate better insight into overall PA levels, as well as improved identification of socioeconomic inequalities in PA.

\section{Competing interests}

The authors declare that they have no competing interests.

\section{Authors' contributions}

AW, JD and JL initiated this specific study and have made substantial contributions to conception and design, acquisition of data and analysis and interpretation of data. All authors (AW, JM, SC, MN, HP, IB, JB, JL) have been involved in drafting the manuscript or revising it critically for important intellectual content and have given final approval of the version to be published.

\section{Acknowledgements}

This work is part of the SPOTLIGHT project, supported by the Seventh Framework Programme (CORDIS FP7) of the European Commission, HEALTH (FP7-HEALTH-2011-two-stage), Grant agreement no. 278186. The content of this article reflects only the authors' views and the European Commission is not liable for any use that may be made of the information contained therein.

\section{Author details}

${ }^{1}$ Department of Epidemiology and Biostatics, EMGO Institute for Health and Care Research, VU University Medical Center Amsterdam, De Boelelaan 1089a, 1081 HV, Amsterdam, The Netherlands. ${ }^{2}$ Department of Movement and Sport Sciences, Ghent University, Ghent, Belgium. ${ }^{3}$ Department of Public Health, Academic Medical Centre, University of Amsterdam, Amsterdam, The Netherlands. ${ }^{4}$ Department of Public and Occupational Health, EMGO Institute for Health and Care Research, VU University Medical Center Amsterdam, Amsterdam, The Netherlands.

Received: 4 August 2015 Accepted: 19 December 2015

Published online: 26 December 2015

\section{References}

1. Taylor RS, Brown A, Ebrahim S, Jolliffe J, Noorani H, Rees K, et al. Exercisebased rehabilitation for patients with coronary heart disease: systematic review and meta-analysis of randomized controlled trials. Am J Med. 2004;116:682-92.

2. Deng HB, Macfarlane DJ, Thomas GN, Lao XQ, Jiang CQ, Cheng KK, et al. Reliability and validity of the IPAQ-Chinese: the Guangzhou Biobank Cohort study. Med Sci Sports Exerc. 2008:40:303-7.

3. Ainsworth BE. How do I measure physical activity in my patients? Questionnaires and objective methods. Br J Sports Med. 2009;43:6-9.

4. Sallis JF, Saelens BE. Assessment of physical activity by self-report: status, limitations, and future directions. Res Q Exerc Sport. 2000;71:1-14.

5. Baranowski T. Validity and reliability of self report measures of physical activity: an information-processing perspective. Res Q Exerc Sport. 1988;59:314-27.

6. Adams S, Matthews CE, Ebbeling CB, Moore CG, Cunningham JE, Fulton J, et al. The effect of social desirability and social approval on self-reports of physical activity. Am J Epidemiol. 2005;161:389-98.

7. Craig CL, Marshall AL, Sjöström M, Bauman AE, Booth ML, Ainsworth BE, et al. International physical activity questionnaire: 12-country reliability and validity. Med Sci Sports Exerc. 2003;195:3508-1381.

8. Prince SA, Adamo KB, Hamel ME, Hardt J, Gorber SC, Tremblay M. A comparison of direct versus self-report measures for assessing physical activity in adults: a systematic review. Int J Behav Nutr Phys Act. 2008:5:56.

9. Silsbury Z, Goldsmith R, Rushton A. Systematic review of the measurement properties of self-report physical activity questionnaires in healthy adult populations. BMJ Open. 2015;5:e008430. 
10. van Poppel M, Chinapaw M, Mokkink LB, van Mechelen W, Terwee CB. Physical activity questionnaires for adults: A systematic review of measurement properties. Sports Med. 2010;40:565-600.

11. Lagerros YT, Mucci LA, Bellocco R, Nyrén O, Bälter O, Bälter KA. Validity and reliability of self-reported total energy expenditure using a novel instrument. Eur J Epidemiol. 2006;21:227-36.

12. Slootmaker SM, Schuit AJ, Chin A, Paw MJM, Seidell JC, Van Mechelen W. Disagreement in physical activity assessed by accelerometer and self-report in subgroups of age, gender, education and weight status. Int J Behav Nutr Phys Act. 2009;6:17.

13. Lakerveld J, Brug J, Bot S, Teixeira PJ, Rutter H, Woodward E, et al. Sustainable prevention of obesity through integrated strategies: The SPOTLIGHT project's conceptual framework and design. BMC Public Health. 2012;12:793.

14. Lakerveld J, Ben Rebah M, Mackenbach JD, Charreire H, Compernolle S, Glonti $\mathrm{K}$, et al. Obesity-related behaviours and BMI in five urban regions across Europe: sampling design and results from the SPOTLIGHT crosssectional survey. BMJ Open. 2015;5:e008505.

15. Luijkx R, de Heus M. The educational system of the Netherlands. In: Schneider SL, editor. The international standard classification of education (ISCED-97). An evaluation of content and criterion validity for 15 European countries. Mannheim: Mannheimer Zentrum für Europäische Sozialforschung; 2008. p. 47-75

16. The IPAQ group. Guidelines for Data processing and Analysis of the International Physical Activity Questionnaire (IPAQ): Short and Long Forms. 2005. Ref Type: Report.

17. Rzewnicki R, Auweele Y, De Bourdeaudhuij I. Addressing overreporting on the International Physical Activity Questionnaire (IPAQ) telephone survey with a population sample. Public Health Nutr. 2003;6:299-305.

18. Montoye H, Kemper H, Saris W, Washburn RA. Measuring physical activity and energy expenditure. Human Kinetics Champaign, IL; 1996.

19. Ekelund U, Sepp H, Brage S, Becker W, Jakes R, Hennings M, et al. Criterionrelated validity of the last 7-day, short form of the International Physical Activity Questionnaire in Swedish adults. Public Health Nutr. 2006;9:258-65.

\section{Submit your next manuscript to BioMed Central and we will help you at every step:}

- We accept pre-submission inquiries

- Our selector tool helps you to find the most relevant journal

- We provide round the clock customer support

- Convenient online submission

- Thorough peer review

- Inclusion in PubMed and all major indexing services

- Maximum visibility for your research

Submit your manuscript at www.biomedcentral.com/submit 